\title{
Assessment of Knowledge, Attitudes and Practices (KAP) on Rheumatic Heart Disease among Senior Medical Students in Cameroon
}

\author{
David Chelo1,2*, Leslie Mbapah Tasha3, Anastase Dzudie Tamdja4, Clovis Nkoke3, \\ Denis Georges Tewafeu ${ }^{3}$, Nelson Njedock ${ }^{4}$, Samuel Kingue ${ }^{4}$ \\ ${ }^{1}$ Mother and Child Center, Chantal BIYA Foundation, Yaoundé, Cameroon \\ ${ }^{2}$ Department of Pediatrics, Faculty of Medicine and Biomedical Sciences, University of Yaoundé 1, Yaoundé, Cameroon \\ ${ }^{3}$ Department of Internal Medicine, University of Buea, Buea, Cameroon \\ ${ }^{4}$ Department of Internal Medicine, Faculty of Medicine and Biomedical Sciences, University of Yaoundé 1, Yaoundé, Cameroun \\ Email: *chelodad6@yahoo.fr
}

How to cite this paper: Chelo, D., Tasha, L.M., Tamdja, A.D., Nkoke, C., Tewafeu, D.G., Njedock, N. and Kingue, S. (2020) Assessment of Knowledge, Attitudes and Practices (KAP) on Rheumatic Heart Disease among Senior Medical Students in Cameroon. World Journal of Cardiovascular Diseases, 10, 363-378.

https://doi.org/10.4236/wjcd.2020.106035

Received: February 25, 2020

Accepted: June 25, 2020

Published: June 28, 2020

Copyright $\odot 2020$ by author(s) and Scientific Research Publishing Inc. This work is licensed under the Creative Commons Attribution International License (CC BY 4.0).

http://creativecommons.org/licenses/by/4.0/

\begin{abstract}
Background: Rheumatic heart disease (RHD) is the commonest cause of valvular heart disease in low and middle-income countries (LMICs). The low cardiologist to patient ratio leaves a big challenge of RHD prevention and management to general practitioners in Cameroon. This makes it important to assess the aptitude of senior medical students who are doctors-to-be on RHD. This could thus give a base on which to increase awareness and decrease the burden of the disease. Therefore, we sort to evaluate the knowledge, attitudes, and practices (KAP) of senior medical students on rheumatic heart disease. General objective: To determine the level of knowledge, attitudes on rheumatic heart disease, and assess practices towards RHD and its prevention. Methodology: A cross-sectional study was conducted in four medical schools in Cameroon for a period of 3 months (from January $1^{\text {st }}$ to April $\left.1^{\text {st }}, 2019\right)$. The senior medical students were recruited using a structured self-administered questionnaire and electronic forms. Data were entered into an excel spreadsheet and analysed with IBM SPSS version 25.0 for windows. The knowledge level was divided into tertiles (poor, moderate and good) while the attitudes and practices were divided into poor or good. Association to KAP was evaluated and Statistical significance was set at $\mathrm{P}<0.05$. Results: In total, 509 senior medical students $\left(6^{\text {th }}\right.$ and $7^{\text {th }}$ year $)$ were recruited. The mean age was 24.6 ( $\mathrm{SD} \pm 1.7$ ) with $53.2 \%$ of students in the 19 to 24 years-old range. There were more females (51.7\%) and level 6 students (50.1\%). Most of the students had moderate knowledge (58.2\%), with good attitudes and practices on rheumatic heart disease and its prevention. One-quarter of the students had good knowledge, attitudes, and practices on rheumatic heart dis-
\end{abstract}


ease. Lecture on RHD, history of sore throat and study in faculty of health science (FHS) was associated with good knowledge, attitudes, and practices on RHD. Conclusion: Despite having most of the senior medical students $\left(6^{\text {th }}\right.$ and $7^{\text {th }}$ years) in Cameroon with moderate to good knowledge of RHD, only a third has an above-average knowledge. There is a modest knowledge of RHD that could be used as an important foundation upon which to build RHD educational programs to expand awareness and understanding. Every 1 in 4 senior medical students have good knowledge, attitude and practice on RHD.

\section{Keywords}

Senior Medical Students, Rheumatic Heart Disease, Cameroon, Attitude, Knowledge, and Practice, General Practitioners

\section{Introduction}

Cardiovascular disease (CVD) is the leading cause of premature death worldwide, with the highest occurrence reported in low and middle-income countries (LMICs) [1]. Rheumatic heart disease (RHD) is one of the most preventable causes of heart disease in children and young adults worldwide and the most common cardiovascular disease in people under 25 years of age [2] [3]. According to the 2016 Global Burden of Diseases (GBD) study, there are 33 million people with rheumatic heart disease(RHD) globally, causing more than 9 million Disability-Adjusted Life Years (DALY) lost and 275,000 to 345,000 deaths each year [4] [5] [6] [7]. RHD is thus a serious public health threat to the LMICs [6] [8]. Amongst cardiovascular diseases (CVD) in children and young adults in Sub Saharan Africa (SSA), RHD accounts for 17\% - 43\% with close to 400,000 deaths annually [9] [10]. The prevalence of echocardiographically diagnosed RHD in Cameroon ranges from $3.1 \%$ to $5.8 \%$ in hospital settings [11] [12].

The effective implementation of the ASAP (Awareness, Surveillance, Advocacy and Prevention) program in Africa is limited by barriers such as limited access to primary health care, the expense of microbiological diagnosis of sore throat, low index of suspicion of ARF/RHD by physicians and poor community awareness [13]. There is also limited data on knowledge, attitudes, and practices (KAP) on RHD in Africa. A study in Zambia on school children with their parents or guardians revealed that $26 \%$ received treatment of sore throat without skilled assessment [14]. A similar study in Sudan on physicians revealed an average physicians' knowledge of the prevention of ARF/RHD [15]. To the best of our knowledge, only one study on RHD awareness has been done in Cameroon; this revealed a low knowledge level on RHD among the general population attending the Buea Regional Hospital [13]. The later study was hospital-based and awoke the need for community and health personnel surveys to better understand the level of awareness on this disease. 
We do not know whether primary healthcare providers trained in Cameroon are adequately empowered to contribute to primordial, primary, secondary and tertiary prevention of RHD in Cameroon to help eradicate the disease [13]. This is evidenced by the paucity of data on studies done on the KAP of RHD among physicians and senior medical students in the country [11] [12] [13].

The low cardiologist to patient ratio leaves the burden of rheumatic heart disease prevention and management to general practitioners in Cameroon. Empowering senior medical students and general practitioners in sensitization, prevention, early detection, and referral will help reduce the disease burden and improve outcomes. Therefore, knowing the gaps in KAP towards RHD in doctors-to-be will help the health and educational institutions to adjust the training curriculum to fill these gaps, hence help to eradicate the disease from our setting.

This study had as objectives to assess the knowledge level of senior medical students on RHD, describe their attitudes towards RHD and its prevention, assess the practices of senior medical students in the prevention of RHD and identify determinants to the KAP on RHD in senior medical students in four medical schools in Cameroon.

\section{Materials and Methods}

\subsection{Study Design and Setting}

This was a school-based cross-sectional study carried out in $6^{\text {th }}$ and $7^{\text {th }}$-year medical students in four medical schools in Cameroon from February to April 2019. These schools are; Faculty of Health Sciences University of Buea (FHS-UB) in SouthWest region, Faculty of Medicine and Biomedical Sciences University of Yaounde 1 (FMBS-UY1) in Centre region, Institut superieur de Technologie Medicale (ISTM) in the Centre region and Institute of Health Sciences, Universite des Montagnes (UdM) in the West region.

\subsection{Variables}

A self-administered structured questionnaire was used in this study (see Appendix). Participants' demographic information and information on their knowledge, attitudes and practices on Rheumatic heart disease. Using the aide of either multiple-choice questions or a three-point categorical scale (Yes, No, Don't know), the level of knowledge on risk factors, aetiology, symptoms, complications, diagnosis, management, and prevention of RHD was tested for each student. Their attitude towards the prevention of RHD was assessed using a five-point Likert response scale (strongly disagree, disagree, no decision, agree, strongly agree). Finally, their hypothetical practices on the management and prevention of RHD and its risk factors were measured using the four-point Likert response scale (very unlikely, unlikely, likely and very likely). The predictor variables considered were: Age, gender, grade level, medical school, lectures on RHD, history of sore throat, history of RHD, seen case of ARF or RHD. The outcome variables were: knowledge (poor, moderate, good), attitudes (poor or good), and practices 
(poor or good) on RHD.

\subsection{Sampling}

A two-stage sampling process was done. Firstly, four out of six medical schools with students in the clinical years of study were selected by a simple random sampling technique (balloting). Secondly, a list of students $6^{\text {th }}$ and $7^{\text {th }}$ students from the schools was established and they were met by convenience on their school campuses and teaching hospitals during their breaks and free periods. The students that could not be met physically were phoned and the Google electronic form was sent to their email addresses. Using Cochran's formula, the minimum sample size was estimated at 423 students. A structured questionnaire adapted from both the standardized KAP questionnaire, from the KAP Manual published in 2014 by the Food and Agricultural Organization [16] and that used by Nkoke et al. in assessing the awareness of rheumatic heart disease in the South-west region of Cameroon [13] was used in this study. The questionnaire was pretested with 10 participants (five from each level) and necessary adjustments were made. The questionnaire was self-administered and supervised by three data collectors $\left(7^{\text {th }}\right.$-year medical students) who collected back the various responses immediately upon completion by the participants at each study site. The questionnaire was designed in both English and French. The students used their first language for a better understanding.

\subsection{Data Analysis}

Data generated from the study were entered in an excel spreadsheet and analysed with IBM SPSS version 25 for Windows.

We assessed the knowledge level with a total of 22 questions. The answer YES $=1, \mathrm{NO}=0$, and DO NOT KNOW $=0$ points respectively. For the MCQ, the right answer $=1$, and wrong $=0$ respectively. The knowledge level score was divided into tertiles, categorized as poor ( 0 - 8 points), moderate ( 9 - 13 points) and good (14 - 22 points). Some questions were analysed individually.

We assessed attitudes using 12 questions with 5-points Likert scale responses. Globally, attitude was rated as good if total response $\geq 6$, poor if response $<6$. Some questions were analysed individually

We assessed practices using 10 questions. Overall, practice was rated as good if total response $\geq 5$ and poor if response $<5$. Some questions were analysed individually

Finally, various determining factors were compared to knowledge, attitudes, and practices for any statistical significance using the Chi-square test with Odd ratio (OR) used to determine the strength of the association. A p-Value $<0.05$ was considered statistically significant for the observed association.

\subsection{Ethical Statement}

This study was approved by the administrative authorities of the four medical 
schools. The study was explained to all eligible participants in their first language (English or French) for better understanding. Participants who consented to our study signed a written consent form. The students benefited from education on RHD and its prevention after filling the questionnaire. The questionnaire was anonymous to protect the identity of participants.

\section{Results}

\subsection{Socio-Demographic Characteristics}

In all, we reached out to 509 medical students, with a response rate of $90.1 \%$. The mean age of the students was $24.6(\mathrm{SD} \pm 1.7$ ) with $53.2 \%$ of students between the age group 19 to 24 years. There were 263 (51.7\%) females and 255 (50.1\%) $6^{\text {th }}$-year students. The distribution of participants per school was as follows; FHS-UB 169 (33.2\%), FMBS-UY1 164 (32.2\%), UdM 120 (23.6\%) and ISTM 56 (11.0\%).

A prior history of sore throat was reported in 417 (81.9\%) students, with 20 (3.9\%) students who had been diagnosed with acute rheumatic fever and 3 (0.6\%) diagnosed with Rheumatic heart disease.

Students who had had a formal lecture on RHD in either the $4^{\text {th }}$ and or $5^{\text {th }}$ year made up $87.2 \%$ (444) of our study. Of the 444 students, 265 (59.7\%) had one lecture while 179 (40.3\%) had two or more lectures. In this study, 238 (46.8\%) had seen at least one case of Acute rheumatic fever, while 171 (33.6\%) had seen at least one case of Rheumatic heart disease.

\subsection{Knowledge of Medical Students on Rheumatic Heart Disease}

\section{Global knowledge level on rheumatic heart disease}

The overall knowledge level of senior medical students on Rheumatic heart disease was moderate 296 (58.2\%), with 159 (31.2\%) of students having a good knowledge level. The mean knowledge score was 11.97 ( $\mathrm{SD} \pm 3.0$ ) out of 22.

\section{Knowledge on prevention of RHD}

In our study, up to $30.1 \%$ of students thought that amoxicillin was the drug of choice for secondary prophylaxis for acute rheumatic fever or rheumatic heart disease. The minimum duration of secondary prophylaxis was known by $14.5 \%$ of students, and $84.7 \%$ responded that Benzathine penicillin is the drug of choice for the treatment of sore throat to prevent acute rheumatic fever.

Global attitudes level, and attitudes towards preventive measures on RHD

In this study, $456(89.6 \%)$ students had good attitudes towards rheumatic heart disease and its prevention. With a mean attitude score of 7.97 (SD \pm 1.9$)$ out of 12 .

Global practice level, and practices on RHD prevention

The majority of students had good practices $(404,79.4 \%)$ on the prevention of RHD. With a mean practice score of $6.13(\mathrm{SD} \pm 1.9)$ out of 10 .

In this study, $72.7 \%$ of students were unlikely to suspect a diagnosis of ARF in a patient with mono-arthritis and $65.5 \%$ were unlikely to admit a patient with 
suspected ARF. More so, $18.9 \%$ of students were unlikely to recommend secondary prophylaxis with antibiotics in a patient with ARF/RHD and $21.4 \%$ were unlikely to suspect RHD in a patient with a heart murmur. However, $78.6 \%$ of the students were very likely to request echocardiography in patients with ARF. Furthermore, 69\% indicated the willingness to include RHD awareness in their health campaign programs, and $71.9 \%$ indicated a willingness to advocate for ARF/RHD registry in Cameroon.

Determinants to the Knowledge, Attitudes, and Practices Combined

In our study, 128 (25.1\%) participants had good knowledge, attitudes, and practice combined on RHD. The KAP on RHD was significantly associated with being a student from FHS-UB [p < 0.001, OR: 3.0 (95\% CI: 2.0 - 4.5)], having had lecture on RHD [p = 0.004, OR: 3.1 (95\% CI: $1.4-7.0)$ ], and a history of sore throat [p = 0.015, OR: 2.1 (95\% CI: 1.1 - 3.9)] (Table 1).

Table 1. Determinants to good knowledge attitudes and practices of medical students on rheumatic heart disease.

\begin{tabular}{|c|c|c|c|}
\hline Variable & Percentage (\%) & OR $(95 \% \mathrm{CI})$ & $\mathrm{p}$-value \\
\hline \multicolumn{4}{|c|}{ Age $\leq 24$ years } \\
\hline Yes & 23.2 & $0.8(0.5-1.2)$ & 0.292 \\
\hline No & 27.3 & 1 & \\
\hline \multicolumn{4}{|l|}{ Female } \\
\hline Yes & 25.9 & $1.1(0.7-1.6)$ & 0.703 \\
\hline No & 24.4 & 1 & \\
\hline \multicolumn{4}{|l|}{ FHS-UB } \\
\hline Yes & 36.6 & $3.0(2.0-4.5)$ & $<0.001^{*}$ \\
\hline No & 17.9 & 1 & \\
\hline \multicolumn{4}{|l|}{ Level 7} \\
\hline Yes & 26.8 & $1.2(0.8-1.8)$ & 0.399 \\
\hline No & 23.5 & 1 & \\
\hline \multicolumn{4}{|c|}{ Lecture on RHD } \\
\hline Yes & 27.3 & $3.1(1.4-7.0)$ & $0.004^{*}$ \\
\hline No & 10.8 & 1 & \\
\hline \multicolumn{4}{|c|}{$\geq 2$ lectures on RHD } \\
\hline Yes & 30.2 & $1.0(0.7-1.6)$ & 0.855 \\
\hline No & 24.8 & 1 & \\
\hline \multicolumn{4}{|c|}{ History of sore throat } \\
\hline Yes & 27.3 & $2.1(1.1-3.9)$ & $0.015^{*}$ \\
\hline No & 15.2 & 1 & \\
\hline \multicolumn{4}{|c|}{ History of ARF } \\
\hline Yes & 15.0 & $0.5(0.1-1.8)$ & 0.286 \\
\hline No & 25.6 & 1 & \\
\hline
\end{tabular}




\section{Continued}

\begin{tabular}{cccc}
\hline $\begin{array}{c}\text { History of RHD } \\
\text { Yes }\end{array}$ & 33.3 & $1.5(0.1-16.6)$ & 0.743 \\
No & 25.1 & 1 & \\
Seen case of ARF & & & 0.559 \\
Yes & 23.9 & $0.9(0.6-1.3)$ & \\
No & 26.2 & 1 & 0.280 \\
Seen case of RHD & & $1.3(0.8-1.9)$ & \\
Yes & 28.1 & 1 & \\
No & 23.7 & 1 & \\
\hline
\end{tabular}

* Statistically significant. OR, Odd ratio; CI, Confidence interval; FHS-UB, Faculty of health sciences, University of Buea; ARF, Acute rheumatic fever; RHD, Rheumatic heart disease.

\section{Discussion}

This is a pioneer study assessing rheumatic heart disease awareness among medical students in Africa. We report here that only $25 \%$ of medical students are adequately equipped in a combination of knowledge, attitudes and practices towards RHD in Cameroon by their sixth to the seventh year of studies.

Out of three main parameters assessed, knowledge had the lowest proportion of students to be graded good, accounting for the low overall proportion of students who were good in all three parameters.

In this study, less than a third (31.2\%) of medical students had good knowledge of RHD and ARF. This result is superimposable to the report from Sudan by Ali and co-workers who found that $30 \%$ of practicing physicians had good knowledge of RHD [17]. Despite having a comparable report with this other sub-Saharan African study, it still worrying to have only 1 in 3 senior medical students with above-average knowledge on RHD. It is evident therefore that if actions were taken to optimise the knowledge of medical students on RHD, this could be translated in the field to knowledgeable practicing physicians as per RHD.

Though most students (94.5\%) were aware of the correlation between a sore throat and ARF/RHD, only $14.5 \%$ were aware of the minimum duration of secondary prophylaxis which is 10 years [18]. Manase Maria had similar disproportionate findings in Tanzania, though a greater proportion of health care providers $(67.8 \%)$ knew of the minimum duration of secondary prophylaxis.

Most of our participants (89.6\%) portrayed good attitudes towards RHD and its prevention. The direct and indirect cost of management of RHD and its complications are very high especially in a resource-limited setting like ours [19] [20]. Therefore, a focus on primordial, primary and secondary prevention is of utmost importance making use of measures such as: raising disease awareness through appropriate sensitisation on RHD and reporting of cases, improving socio-economic status, avoiding ineffective locally made home remedies for sore 
throat cases, consulting a skilled health care professional for appropriate assessment and treatment with antibiotics if need be. Besides, screening school-aged children for early detection of asymptomatic cases which constitute a high burden of disease [21] and sending for cardiologist follow up and secondary prophylaxis with Benzathine penicillin $G$ should be envisaged.

In our study, close to $20 \%$ of participants disagreed on the necessity to treat a sore throat with antibiotics to reduce the risk of ARF. This is lower compared to what Tamader et al. in Saudi Arabia reported, where $68.2 \%$ of doctors did not prescribe antibiotics for pharyngitis treatment [22]. This difference may be because the doctors used clinical decision rule to identify bacterial pharyngitis before antibiotics use and are more experienced with it. It is well known that most sore throat is viral and may not require antibiotics. However, antibiotics are the cornerstone of the prevention of ARF/RHD resulting from Group A streptococcal (GAS) pharyngitis. Recent guidelines recommend the stratification of patients into high and low risk for ARF to guide the choice of the timing for antibiotics. Though the high prevalence of sore throat and ARF in our setting may explain why most students will give antibiotics for sore throat, we must admit that the answer to the question is ambiguous since it is patient-dependent and not on the presence or absence of sore throat dependent.

Though the decision to use home remedies is unconventional and has no scientific backing, close to half $(44.1 \%)$ of the students still think that these remedies may be useful. Whether or not the students think they could be used singly or in combination with conventional therapy cannot be answered by this report and thus require further investigations as this may stem from their personal experience with these measures.

We found out that most students (79.4\%) portrayed good practices towards RHD prevention and were likely (81.1\%) to recommend secondary prophylaxis with antibiotics in patients with $\mathrm{ARF} / \mathrm{RHD}$ to prevent $\mathrm{ARF}$ recurrence and slow down RHD progression [23] [24]; suspect RHD (78.6\%) in a patient with a heart murmur; and request echocardiography (78.6\%) in patients with ARF to identify and grade any associated carditis [25] [26]. However, up to $72.1 \%$ were unlikely to suspect a diagnosis of ARF in patients with mono-arthritis and over $65 \%$ were unlikely to admit a patient with suspected ARF as recommended by scientific societies. This is probably because most of the students had not been exposed to ARF cases and had thus not considered mastering the management algorithm of the disease.

Close to $70 \%$ of participants were likely to include ARF/RHD awareness in their health campaign program and were equally likely to advocate for an ARF/ RHD registry in Cameroon-subjects which are in line with the ASAP (awareness, surveillance, advocacy, and prevention) program of the Pan-African Society of Cardiology [27]. It is thus deducible that if a continuous emphasis was laid on this subject in medical schools and continuous medical education, many would take the lead in projects that would contribute to eradicating the disease from 


\section{Sub-Saharan Africa.}

Good knowledge was significantly associated with being a student from FHS-UB. More students from FHS-UB have good knowledge (50.3\%) than those not from FHS-UB with good knowledge (21.8\%). This may be because students from FHS-UB were exposed to at least two formal lectures on RHD in paediatrics and internal medicine in their $4^{\text {th }}$ and $5^{\text {th }}$ year respectively while students from the other schools had only one lecture either in paediatrics or internal medicine, in $4^{\text {th }}$ or $5^{\text {th }}$ year. In addition, having a formal lecture on RHD was also significantly associated with good knowledge.

There was a significant association between having a history of sore throat and a good knowledge of RHD. More students with a history of sore throat had a good knowledge level (33.3\%) than those without a history of sore throat with good knowledge (21.7\%). This could be because students with such exposure are motivated to study extensively about the disease. Having a formal lecture on RHD was the only factor significantly associated with good attitudes towards RHD.

A quarter of the students were graded "good" on combined Knowledge, Attitudes, and Practices assessment on RHD. This was significantly associated with having a formal lecture on RHD, a history of sore throat and schooling at FHSUB.

We provide here one of the first KAP on RHD among medical students in Cameroon. Nevertheless, our results may have a few limitations. A nonresponse bias-resulting from the $10 \%$ of students who did participate in the study-as well as reporting and recall bias despite all the measures that were taken to prevent this; including confidentiality, pre-test evaluation of the questionnaire and sufficient time was given for each responder. Though the students were reassured that it was a simple survey and that valid response were needed, we can not prove that those who took the online questionnaire all answered without checking other sources.

\section{Conclusion}

Attitudes and practices towards rheumatic heart disease can easily be interpolated from the attitude and practice of similar conditions, but adequate knowledge may require specific training. Despite having most of the senior medical students in Cameroon with moderate to good knowledge on RHD, only a third had an above-average knowledge. Thus, there is a modest knowledge base on RHD that could be used as an important foundation upon which to build RHD educational programs to expand awareness and understanding.

\section{Recommendations}

The ministry of public health of Cameroon should take steps to establish nationwide awareness programs on RHD by using outlets like media houses, billboards, health campaign programs, etc. 
The ministry of higher education of Cameroon should emphasize RHD in the harmonised national curriculum for medical schools like it's done with other diseases like HIV/AIDS.

Researchers should conduct further studies to determine if increasing knowledge leads to behavioural changes that could help decrease the burden of RHD in our setting. And to also conduct a KAP on RHD among physicians in Cameroon.

\section{Conflicts of Interest}

The authors declare no conflicts of interest regarding the publication of this paper.

\section{References}

[1] Palafox, B., Mocumbi, A.O., Kumar, R.K., Ali, S.K.M., Kennedy, E., Haileamlak, A., et al. (2017) The WHF Roadmap for Reducing CV Morbidity and Mortality through Prevention and Control of RHD. Global Heart, 12, 47-62. https://inkinghub.elsevier.com/retrieve/pii/S221181601630789X https://doi.org/10.1016/j.gheart.2016.12.001

[2] Ali, S., Awadallah, H., Al Hamim, A., Al Hussein, H., Al Amin Al Sunni, M., Bushari, T., et al. (2018) Handheld Echocardiography for Screening and Control of Rheumatic Heart Disease Study in Gezira State, Sudan: A Double Approach Model. Cardiovascular Diagnosis and Therapy, 8, 500-507. https://www.ncbi.nlm.nih.gov/pmc/articles/PMC6129838 https://doi.org/10.21037/cdt.2018.07.04

[3] Dougherty, S., Khorsandi, M. and Herbst, P. (2017) Rheumatic Heart Disease Screening: Current Concepts and Challenges. Annals of Pediatric Cardiology, 10, 39-49. https://www.ncbi.nlm.nih.gov/pmc/articles/PMC5241843 https://doi.org/10.4103/0974-2069.197051

[4] Carapetis, J.R., Beaton, A., Cunningham, M.W., Guilherme, L., Karthikeyan, G., Mayosi, B.M., et al. (2016) Acute Rheumatic Fever and Rheumatic Heart Disease. Nature Reviews Disease Primers, 2, Article No. 15084. http://www.nature.com/articles/nrdp201584

[5] Sika-Paotonu, D., Beaton, A. and Carapetis, J. (2019) Epidemiology and Global Burden of Rheumatic Heart Disease. Oxford University Press, Oxford. http://oxfordmedicine.com/view/10.1093/med/9780198784906.001.0001/med-97801 98784906-chapter-65 https://doi.org/10.1093/med/9780198784906.003.0065

[6] Zühlke, L., Karthikeyan, G., Engel, M.E., Rangarajan, S., Mackie, P., Cupido-Katya Mauff, B., et al. (2016) Clinical Outcomes in 3343 Children and Adults with Rheumatic Heart Disease from 14 Low- and Middle-Income Countries: Two-Year Follow-Up of the Global Rheumatic Heart Disease Registry (the REMEDY Study). Circulation, 134, 1456-1466.

[7] Saxena, A. (2016) Task Shifting Rheumatic Heart Disease Screening to Non-Experts. The Lancet Global Health, 4, e349-50.

https://www.thelancet.com/journals/langlo/article/PIIS2214-109X(16)30077-8/abstract https://doi.org/10.1016/S2214-109X(16)30077-8

[8] Watkins, D.A., Johnson, C.O., Colquhoun, S.M., Karthikeyan, G., Beaton, A., Bukhman, G., et al. (2017) Global, Regional, and National Burden of Rheumatic Heart 
Disease, 1990-2015. New England Journal of Medicine, 377, 713-722. https://doi.org/10.1056/NEJMoa1603693

[9] Anthony, J., Osman, A. and Sani, M.U. (2016) Valvular Heart Disease in Pregnancy. Cardiovascular Journal of Africa, 27, 111-118. https://doi.org/10.5830/CVJA-2016-052

[10] Sliwa, K., Carrington, M., Mayosi, B.M., Zigiriadis, E., Mvungi, R. and Stewart, S. (2010) Incidence and Characteristics of Newly Diagnosed Rheumatic Heart Disease in Urban African Adults: Insights from the Heart of Soweto Study. European Heart Journal, 31, 719-727. https://doi.org/10.1093/eurheartj/ehp530

[11] Nkoke, C., Lekoubou, A., Dzudie, A., Jingi, A.M., Kingue, S., Menanga, A., et al. (2016) Echocardiographic Pattern of Rheumatic Valvular Disease in a Contemporary Sub-Saharan African Pediatric Population: An Audit of a Major Cardiac Ultrasound Unit in Yaounde, Cameroon. BMC Pediatrics, 16, 43. https://doi.org/10.1186/s12887-016-0584-Z

[12] Nkoke, C., Dzudie, A., Makoge, C., Luchuo, E.B., Jingi, A.M. and Kingue, S. (2018) Rheumatic Heart Disease in the South West Region of Cameroon: A Hospital Based Echocardiographic Study. BMC Research Notes, 11, Article No. 221. https://bmcresnotes.biomedcentral.com/articles/10.1186/s13104-018-3341-6 https://doi.org/10.1186/s13104-018-3341-6

[13] Nkoke, C., Luchuo, E.B., Jingi, A.M. and Makoge, C. (2018) Rheumatic Heart Disease Awareness in the South West Region of Cameroon: A Hospital Based Survey in a Sub-Saharan African Setting. PLOS ONE, 13, e0203864.

[14] Musuku, J., Lungu, J.C., Machila, E., Jones, C., Colin, L., Schwaninger, S., et al. (2017) Epidemiology of Pharyngitis as Reported by Zambian School Children and Their Families: Implications for Demand-Side Interventions to Prevent Rheumatic Heart Disease. BMC Infectious Diseases, 17, 473. https://doi.org/10.1186/s12879-017-2563-x

[15] Osman, G.M., Abdelrahman, S.M.K. and Ali, S.K.M. (2015) Evaluation of Physicians' Knowledge about Prevention of Rheumatic Fever and Rheumatic Heart Disease before and after a Teaching Session. Sudanese Journal of Paediatrics, 15, 37-42. https://www.ncbi.nlm.nih.gov/pmc/articles/PMC4958660

[16] Fautsch Macías, Y. and Glasauer, P. (2014) Guidelines for Assessing Nutrition-Related Knowledge, Attitudes and Practices. Food and Agriculture Organization of the United Nations. http://www.fao.org/family-farming/detail/fr/c/284518

[17] Ali, S., et al. (2018) Handheld Echocardiography for Screening and Control of Rheumatic Heart Disease Study in Gezira State, Sudan: A Double Approach Model. Cardiovascular Diagnosis and Therapy, 8, 500-507. https://www.ncbi.nlm.nih.gov/pmc/articles/PMC6129838/pdf/cdt-08-04-500.pdf

[18] Carapetis, J., et al. (2012) The Australian Guideline for Prevention, Diagnosis and Management of Acute Rheumatic Fever and Rheumatic Heart Disease (2nd Edition).

[19] North, D.A., Heynes, R.A., Lennon, D.R. and Neutze, J. (1993) Analysis of Costs of Acute Rheumatic Fever and Rheumatic Heart Disease in Auckland. New Zealand Medical Journal, 106, 400-403. http://europepmc.org/abstract/med/8377955

[20] Watkins, D.A., Mvundura, M., Nordet, P. and Mayosi, B.M. (2015) A Cost-Effectiveness Analysis of a Program to Control Rheumatic Fever and Rheumatic Heart Disease in Pinar del Rio, Cuba. PLoS ONE, 10, e0121363.

https://journals.plos.org/plosone/article?id=10.1371/journal.pone.0121363 https://doi.org/10.1371/journal.pone.0121363 
[21] Yadeta, D., et al. (2016) Prevalence of Rheumatic Heart Disease among School Children in Ethiopia: A Multisite Echocardiography-Based Screening. International Journal of Cardiology, 221, 260-263.

https://www.internationaljournalofcardiology.com/article/S0167-5273(16)31242-6/a $\underline{\text { bstract }}$

[22] Aloofy, T.A., et al. (2017) Public Knowledge and Practice of Sore Throat Management among Visitors of Primary Care Clinic in Riyadh, Saudi Arabia. Journal of Advances in Health and Medical Sciences, 3, 1-8.

https://doi.org/10.20474/jahms3.1.1

http://www.tafpublications.com/platform/Articles/full-jahms3.1.1.php

[23] Kevat, P.M., et al. (2017) Adherence to Secondary Prophylaxis for Acute Rheumatic Fever and Rheumatic Heart Disease: A Systematic Review. Current Cardiology Reviews, 13, 155-166. https://europepmc.org/articles/pmc5452151?pdf=render https://doi.org/10.2174/1573403X13666170116120828

[24] Ralph, A.P., et al. (2016) Improving Delivery of Secondary Prophylaxis for Rheumatic Heart Disease in Remote Indigenous Communities: Study Protocol for a Stepped-Wedge Randomised Trial. Trials, 17, 51. https://trialsjournal.biomedcentral.com/track/pdf/10.1186/s13063-016-1166-y

[25] Rémond, M., Atkinson, D., White, A., Brown, A., Carapetis, J., Remenyi, B., et al. (2015) Are Minor Echocardiographic Changes Associated with an Increased Risk of Acute Rheumatic Fever or Progression to Rheumatic Heart Disease? International Journal of Cardiology, 198, 117-122. https://doi.org/10.1016/j.ijcard.2015.07.005

[26] Beaton, et al. (2012) Echocardiography Screening for Rheumatic Heart Disease in Ugandan Schoolchildren. Circulation, 125, 3127-3132. https://doi.org/10.1161/CIRCULATIONAHA.112.147538

[27] Mayosi, B.M. (2016) National Rheumatic Fever Week: The Status of Rheumatic Heart Disease in South Africa. South African Medical Journal, 106, 740-741. http://www.samj.org.za/index.php/samj/article/download/11253/7512 


\section{Appendix: Data Collection Questionnaire}

\section{SECTION 1: DEMOGRAPHIC INFORMATION}

1) Last two digits of phone number

2) Age

3) Gender: a) male b) female

4) Grade level: a) level 4 b) level 5 c) level 6 d) level 7

5) Faculty: a) FHS-UB b) FMBS-UY1 d) ISTM e) UDM

6) Marital status: a) single b) married c) divorced d) widowed

7) Nationality: a) Cameroonian b) Foreign (specify)

\section{SECTION 2: PAST MEDICAL HISTORY}

8) Have you ever had a sore throat? a) yes b) no c) don't know

9) Have you ever been diagnosed with acute rheumatic fever: a) yes b) no c) don't know

10) Have you been diagnosed with rheumatic heart disease? a) yes b) no c) don't know

11) Have you had formal lectures on Rheumatic heart disease? a) Yes b) no c) don't know.

If no, skip question 12

12) For how many semesters? a) 1 b) 2 c) 3 d) more than 3

13) Have you ever seen a patient with acute rheumatic fever? a) yes b) no c) don't know

14) Have you ever seen a patient with rheumatic heart disease? a) Yes b) no. c) don't know

SECTION 3: KNOWLEDGE ON RHEUMATIC HEART DISEASE (answer by yes, no, I don't know, or mark the right answer).

15) What causes rheumatic heart disease?

a) Age b) scarlet fever b) acute rheumatic fever d) virus e) don't know

16) What is the clinical syndrome of acute rheumatic fever?

a) Sydenham chorea, carditis, erythema nodosum, arthritis, subcutaneous nodules.

b) Sydenham chorea, carditis, erythema marginatum, arthritis, subcutaneous nodules.

c) Sydenham chorea, carditis, erythema nodosum, arthralgia, subcutaneous nodule

e) Don't know

17) Can a sore throat cause heart disease? a) yes b) no c) don't know.

18) If yes, which germ is responsible? a) virus b) staphylococcus c) streptococcus d) group A streptococcus e) don't know

19) Which strain of the germ is implicated? a) L protein b) $N$ protein c) $M$ protein d) $P$ protein e) don't know

20) What is the duration from a sore throat to the onset of acute rheumatic fever?

a) 5 days b) 1 to 2 weeks c) 1 month d) 2 months e) don't know 
21) Within which time range does the treatment of sore throat have to be initiated to reduce the risk of acute rheumatic fever?

a) 14 days b) 21 days c) 9 days d) 30 days e) don't know

22) Which treatment is appropriate for a sore throat to prevent acute rheumatic fever and rheumatic heart disease?

a) Benzathine penicillin $G$ b) vancomycin c) azithromycin d) acyclovir e) don't know

23) Carditis in acute rheumatic fever most often persists with the resolution of other symptoms. a) yes b) no c) don't know

24) Rheumatic heart disease can occur without prior evident acute rheumatic fever.

a) Yes b) no c) don't know

25) Which lesion is always associated with carditis in a patient with acute rheumatic fever? a) erythema marginatum b) subcutaneous nodules c) conjunctivitis d) don't know 1

26) Can indolent carditis alone fit the criteria for the diagnosis of acute rheumatic fever?

a) Yes b) no c) don't know

27) Patients with acute rheumatic fever or rheumatic heart disease should be placed on secondary prophylactic antibiotics. a) yes b) no c) don't know

If no or don't know, move to question 31

28) Which is the drug of choice for prophylaxis?

a) Amoxicillin b) penicillin v c) benzathine penicillin d) ceftriaxone e) Don't know

29) What is the frequency of prophylactic antibiotics?

a) 2 weekly b) 4 weekly c) 3 monthly d) 6 monthly e) Don't know

30) A patient should take the prophylaxis for a minimum of?

a) 5 years b) 10 years c) 20 years d) 30 years e) Don't know

31) What are the complications of rheumatic heart disease?

a) Stroke, atrial fibrillation, heart failure b) deep venous thrombosis, infective endocarditis, renal failure c) pulmonary hypertension, pneumonia, heart failure, d) Don't know

32) Carditis in acute rheumatic fever is treated with?

a) NSAID b) paracetamol c) corticosteroid d) don't know

33) Which valve is most commonly involved in rheumatic heart disease?

a) Tricuspid b) aortic c) mitral d) pulmonic e) Don't know

34) The disease presentation in developing countries is most commonly characterised by?

a) Regurgitation b) stenosis c) don't know

35) Should some patients with rheumatic heart disease be placed on anticoagulants?

a) Yes b) no c) don't know

36) One of the management of rheumatic heart disease involves surgery.

a) Yes b) no c) don't know 
SECTION 4: ATTITUDES TOWARDS RHEUMATIC HEART DISEASE AND ITS PREVENTION

37) Do you think it's necessary to treat a sore throat with antibiotics?

1-Strongly disagree 2-Disagree 3-No decision 4-Agree 5-Strongly agree

38) Will you recommend everyone with a sore throat to consult a doctor?

1-Strongly disagree 2-Disagree 3-No decision 4-Agree 5-Strongly agree

39) Other home measures appropriate for the management of sore throat.

1-Strongly disagree 2-Disagree 3-No decision 4-Agree 5-Strongly agree

40) Rheumatic heart disease is associated with low-socioeconomic status

1-Strongly disagree 2-Disagree 3-No decision 4-Agree 5-Strongly agree

41) Reducing overcrowding reduces the risk of sore throat

1-Strongly disagree 2-Disagree 3-No decision 4-Agree 5-Strongly agree

42) Acute rheumatic fever and rheumatic heart disease are underreported in Cameroon.

1-Strongly disagree 2-Disagree 3-No decision 4-Agree 5-Strongly agree

43) Sensitization on rheumatic heart disease is appropriate in Cameroon

1-Strongly disagree 2-Disagree 3-No decision 4-Agree 5-Strongly agree

44) Rheumatic heart disease is well taught in medical schools in Cameroon.

1-Strongly disagree 2-Disagree 3-No decision 4-Agree 5-Strongly agree

45) Will you recommend echocardiography in a patient with acute rheumatic fever?

1-Strongly disagree 2-Disagree 3-No decision 4-Agree 5-Strongly agree

46) Acute rheumatic fever can present as mono-arthritis.

1-Strongly disagree 2-Disagree 3-No decision 4-Agree 5-Strongly agree

47) Do you recommend screening for rheumatic heart disease in all medical students?

1-Strongly disagree 2-Disagree 3-No decision 4-Agree 5-Strongly agree

48) Will you recommend cardiologist consultation in all patients with rheumatic heart disease?

1-Strongly disagree 2-Disagree 3-No decision 4-Agree 5-Strongly agree

SECTION 5: PRACTICES TOWARDS RHEUMATIC HEART DISEASE

AND ITS PREVENTION (answer; answer very unlikely, unlikely, likely, or very likely)

49) How likely will you consult a doctor when you have a sore throat?

1-Very Unlikely 2-Unlikely 3-Likely 4-Very Likely

50) How likely will you ask someone with a sore throat to seek healthcare?

1-Very Unlikely 2-Unlikely 3-Likely 4-Very Likely

51) How likely will you ask a patient with a sore throat to take a home prescription?

1-Very Unlikely 2-Unlikely 3-Likely 4-Very Likely

52) How likely will you consider the diagnosis of acute rheumatic fever in a patient with monoarthritis?

1-Very Unlikely 2-Unlikely 3-Likely 4-Very Likely 
53) How likely are you not to admit a patient with suspected acute rheumatic fever?

1-Very Unlikely 2-Unlikely 3-Likely 4-Very Likely

54) How likely are you to request an echocardiogram in a patient with acute rheumatic fever?

1-Very Unlikely 2-Unlikely 3-Likely 4-Very Likely

55) How likely are you to suspect rheumatic heart disease in a patient with a heart murmur?

1-Very Unlikely 2-Unlikely 3-Likely 4-Very Likely

56) How likely are you to recommend for secondary prophylaxis in a patient with acute rheumatic fever or rheumatic heart disease?

1-Very Unlikely 2-Unlikely 3-Likely 4-Very Likely

57) How likely are you to include the awareness of rheumatic heart disease in your health campaign programs?

1-Very Unlikely 2-Unlikely 3-Likely 4-Very Likely

58) How likely are you to advocate for the establishment of a rheumatic heart disease registry in Cameroon?

1-Very Unlikely 2-Unlikely 3-Likely 4-Very Likely 